\title{
The Comparison Analysis of China and Foreign Countries to Deal with the Economic Risk by Epidemic, in Terms of Monetary and Fiscal Policy
}

\author{
Zhenchuan Jiang1, Xuanxuan Wang2,3*, Huanlan Wang4*, Guo Lu ${ }^{5 *}$, Guohong Wang6\#, Xun Gong7,8\# \\ ${ }^{1}$ Graduate School of Lyceum of the Philippines University, Manila, Philippines \\ ${ }^{2}$ Clinical College of Hubei University of Chinese Medicine, Wuhan, China \\ ${ }^{3}$ Department of Integrative Chinese and Western medicine, Hubei Cancer Hospital, Wuhan, China \\ ${ }^{4}$ Wuhan Hospital of Traditional Chinese and Western Medicine of Tongji Medical College of Huazhong University of \\ Science and Technology, Wuhan, China \\ ${ }^{5}$ Hainan Medical University, Haikou, China \\ ${ }^{6}$ Union Hospital Affiliated to Tongji Medical College of Huazhong University of Science and Technology, Wuhan, China \\ ${ }^{7}$ School of Medicine and Health Management, Tongji Medical College, Huazhong University of Science and Technology, \\ Wuhan, China \\ ${ }^{8}$ Civil-Military Inosculation and New Material Industry Development Center of Huludao City, Huludao, China \\ Email: jiangzc0810@163.com, *caidi87@163.com, ${ }^{*} 48656634 @ q q . c o m,{ }^{*} 78318148 @ q q . c o m,{ }^{*}$ guohongwang2003@163.com, \\ \#gongxun83@aliyun.com
}

How to cite this paper: Jiang, Z. C., Wang, X. X., Wang, H. L., Lu, G., Wang, G. H., \& Gong, X. (2020). The Comparison Analysis of China and Foreign Countries to Deal with the Economic Risk by Epidemic, in Terms of Monetary and Fiscal Policy. American Journal of Industrial and Business Management, 10, 1605-1610.

https://doi.org/10.4236/ajibm.2020.109102

Received: May 21, 2020

Accepted: September 24, 2020

Published: September 27, 2020

Copyright $\odot 2020$ by author(s) and Scientific Research Publishing Inc. This work is licensed under the Creative Commons Attribution International License (CC BY 4.0).

http://creativecommons.org/licenses/by/4.0/

\begin{abstract}
This year, the most attractive current politics and economy news is the measures taken by governments to deal with the risk caused by the epidemic. It is widely believed that the global economy has suffered seriously from the virus. To deal with that, developed countries such as the US, Canada, Japan, the EU, the developing countries, like China, Brazil has already announced some measures and policy. As a big developing country, China is worthy to be analyzed, compared with different period of itself and other countries.
\end{abstract}

\section{Keywords}

Economic Risk, Epidemic, Monetary Policy, Fiscal Policy

\section{Introduction}

With the globally exploded outbreak of Covid-19, the economy of the whole world has been damaged seriously. Under the heavy pressure, the different gov-

${ }^{\star}$ Co-first authors.

${ }^{\#}$ Corresponding authors. 
ernments have already taken various policies and measures to support business industries. This paper will introduce the monetary policy and fiscal policy taken by China and overseas countries. Horizontally comparing with the differences between China and other countries and analyzing China's measures in different periods as vertical comparison to consider the effective strategy to deal with the risk.

\section{Monetary Policy}

Monetary policy is a common method for a government to boost economy which Central Banks play an important role in the progress. At 23:00 Beijing time on March 3, the federal reserve (FED) makes an emergency announcement to cut the benchmark interest rate by 50 basis points to $1 \%-1.25 \%$ and the excess reserve ratio (IOER) by 50 basis points to $1.1 \%$. The move is the first time since the 2008 financial crisis that the US has cut interest rates between regular policy meetings. On 15th, the FED announces to cut its target range for the federal funds rate by $1 \%$ to between $0 \%$ and $0.25 \%$ and launches a $\$ 700$ billion quantitative easing program to support financial markets to counter the impact of COVID 19 on the US economy (Sina, 2020a; Weilai, 2020). According to statistics, the FED has already enhanced the quantity of money by over 2 trillion (Reference News, 2020).

On March 4th Canada cut its main lending rate by half a percentage point to $1.25 \%$, the first cut since mid-2015 (Long, 2020). On March 13th and 27th the bank of Canada cut interest rates by half a percentage point twice in a row, to 0.25\% (Mofcom, 2020).

On March 11th the Bank of England announces an emergency interest rate decrease of 50 basis points, from $0.75 \%$ to $0.25 \%$, in response to the negative impact of global public health events on the economy. On top of that, the Bank of England keeps its target for bond purchases at $£ 435$ billion, and for corporate bond purchases at $£ 10$ billion. Just a week later, the Bank of England cuts interest rates by another 15 basis points to a record low of $0.1 \%$ and increases its bond-buying program by $£ 200$ billion to $£ 645$ billion (Weilai, 2020).

In addition, the reserve bank of Australia cuts its benchmark interest rate by 25 basis points to a record low of $0.5 \%$. On March 16th the central bank of New Zealand announces it would cut its benchmark interest rate by three-quarters of a $1 \%$ to $0.25 \%$ and keep it there for at least a year because of a "significant deterioration" in economic expectations. On the same day, the bank of Korea also announced an emergency interest rate cut of 50 basis points to $0.75 \%$, which is the first time of benchmark interest rates fallen below 1\% (Sina, 2020b).

Until the beginning of April, China's central bank has already cut the requirement reserve ratio (RRR) third times to release 1.75 trillion yuan for long-term funds (Chen, 2020; Wuhu, 2020). The central bank's seven-day reverse repo rate fell for the third time in recent months, from $2.55 \%$ to $2.2 \%$ (Sina, 2020c). It can be shown on serval resource the medium-term lending facility (MLF) and loan 
prime rate (LPR) also decreases (Fenghuang, 2020). The one-year and five-year LPR falls by 20 basis points and 10 basis points respectively from March, the biggest single drop since last August, when the LPR reform is launched (Zhi, 2020).

\section{Fiscal Policy}

Fiscal policy is mainly including special funds, tax reduction and exemption, residents subsidies, and supporting small and medium-sized enterprises. According to CCTV, the U.S. President Donald trump signs into the $\$ 2.2$ trillion stimulus bill passed by the house and senate on March 27, providing much-needed relief to businesses and individuals. The unprecedented package includes $\$ 500$ billion to help hard-hit industries; $\$ 290$ billion for direct cash transfers to millions of American households, up to $\$ 3000$ each; $\$ 350$ billion in loans to small businesses; $\$ 250$ billion to extend unemployment benefits; at least $\$ 100$ billion will be allocated to hospitals and related health systems (Eastmoney, 2020).

Based on incomplete statistics, other countries such as Germany, France, Japan and Australia have pointed out stimulus packages close to or above $10 \%$ of GDP. The numbers of policies from Spain, Canada, the UK, and many countries have been introduced to deal with the impact of the epidemic (Yang, 2020).

As a powerful economic entity, China also has a list of economic stimulate program for the outbreak. The investment for "new infrastructure" is playing an absolute important role. The "new infrastructure" means innovative technological and new development concepts for infrastructure. It not only includes 5G networks, data centers, artificial intelligence (AI), industrial Internet and other parts of the digital economy, but also includes ultra-high voltage (UHV), high-speed rail transit and charging piles of new energy vehicle (Tian, 2020). It not only includes the basic foundation of digital economy such as cloud technology, but also includes the digital transformation and upgrading of traditional infrastructure (JueCezhuli, 2020). It can be estimated that in 2020, the investment amount would be $¥ 1.2$ trillion yuan (Feng, 2020). In the next years, the investment may be more than $¥ 50$ trillion yuan for almost 22,000 projects (Liang, 2020).

\section{Comparative Analysis}

The common goal of all central banks is to further decrease the cost of commercial banks, thus driving down the interest rate on loans. In addition, its change has a strong signal significance, the deposit benchmark interest rate cut can clearly send the policy signal of the central bank to the market to further increase the counter-cyclical adjustment, showing the official determination to stabilize the economy. Furthermore, in light of national conditions, monetary policies should be more flexible and appropriate. The central banks use measures such as cutting RRR and interest rate as well as increasing loans to support business, especially SMS businesses.

Unlike other countries that cut interest rates or print money directly in the 
first place, China's central bank cut the RRR first and then cut interest rates to ensure that monetary liquidity is not excessive. Gradually, a follow-on adjustment strategy of "cutting reverse repo rate first-following MLF cut at the same extent-cutting LPR last" has been formed. The RRR and interest rate are two tools to maintain reasonably sufficient monetary liquidity; guide interest rates in the lending market to decrease the cost of capital, and use funds to support the real economy.

For enterprises, what they are facing under the impact of the epidemic is the survival problem rather than the pressure of taxes and fees. In the case of shutdowns and no transactions, the effect of tax cuts and fees is small. Therefore, creating new opportunity, and injecting power into the market are important.

Compared to other countries, China's fiscal policy is not only to deal with the exciting risk, but also a strategy to further development. The investment of the "new infrastructure" is also a good opportunity to improve the traditional industrial structure. 5G, big data centers and AI are information network upgrades; UHV is the upgrade of power supply network, intercity high-speed railway, intercity rail transit and travel network. New energy vehicle charging pile is a new trend of energy upgrading and travel choice. The industrial Internet is an industrial upgrade, and it is also related to informatization. It can be concluded that four of the seven areas of the "new infrastructure" are related to informatization, which is a recognized trend for business. The energy industry and trip mode also matter to the national economy, resource and people's livelihood.

The "new infrastructure" takes view in a further picture, but the current outbreak has really accelerated its development. The impact of the epidemic on economic development is obvious, and GDP in the first quarter is bound to be affected. If we want to reduce the negative impact of the epidemic on the economy as soon as possible and restore the economy to the normal track, new vitality to the aggregate demand and supply side need to be given. Focusing on industrial areas represented by "new infrastructure" is positive to drive the production side out of the dilemma. What's more, as the epidemic begins to spread around the world, China will face greater environmental pressure this year and may encounter more difficulties in the growth of external demand. In this context, domestic drive would play a increasing key role in economic development.

Compared to China's former stimulus program, the new one has its own advantages. In 2008, the China government also has a " $¥ 4$ trillion program” to support the economy from the financial crisis. The newly printed money flows directly into all sectors of society, especially some powerful enterprises that are not short of money and have good financing channels, as a result, economy has some issues, such as pushing up costs, squeezing the living space of small and medium-sized enterprises, and causing prices to soar and money to be worthless. Because the industry at that time basically dabble in real estate, also indirectly caused the housing price explosion. However, this time, targeted adjustment is given priority to, such as targeted support and targeted RRR reduction, as well as precise adjustment such as LPR, personal mortgage related tools. 
That year, the "¥4 trillion program" is mainly invested in roads, railways and infrastructure construction, most of which will directly affect people's livelihood, such as driving up housing prices. However, the seven major sectors of "new infrastructure" investment will be less directly related on the economy and people's livelihood, and will not cause a strong impact. Instead, they will drive the economy in a more stable and controllable way.

\section{Conclusion}

In order to deal with the economic issue caused by the epidemic, it is necessary to use existing experience for reference. Not only overseas measures, but also domestic former experience is important. Facing the risk, it is significant to view the new born opportunity rather than short-term interest.

\section{Acknowledgements}

We would like to thanks MD. Huanlan Wang, Dr. Xuan-xuan Wang, Dr. Guohong Wang for having prepared the vehicle used in the study. We are grateful to Dr. Guo Lu for reviewing the manuscript.

\section{Funding}

This research was supported by youth program of high-end science and technology innovation think tank of Chinese Association for Science and Technology (DXB-ZKQN-2017-043).

\section{Conflicts of Interest}

The authors declare no conflicts of interest regarding the publication of this paper.

\section{References}

Chen C. J. (2020). 3 Times in the Year, How Does the Cut of RRR Affect the Debt Building? What Other Monetary Policies Are Available in April. https://www.360kuai.com/pc/detail?url=http\%3A\%2F\%2Fzm.news.so.com\%2Fe56dbb 9e65a578e521953938e82bf5c9\&check=764df22dcdf2b8fa\&uid $=15484592 \% 2 \mathrm{E} 52186134$ 9677200300\%2E1562941115209\%2E8738\&sign=360_e39369d1\&scene=1\&refer_scene= so_92

Eastmoney (2020). \$2 Trillion, the Biggest Fiscal Stimulus in the US. http://forex.eastmoney.com/a/202003251431685288.html

Fenghuang (2020). The LPR Rate Went Down Again in April! Five-Year Number Down 10 Basis Points. https://www.360kuai.com/pc/94854d40123769706?cota=3\&kuai_so=1\&sign=360_57c3 bbd1\&refer_scene=so_1

Feng, N. N. (2020). According to the Bank of China Research Institute, the Investment Scale of "New Infrastructure" will Reach 1.2 Trillion Yuan in 2020. http://bank.hexun.com/2020-03-27/200778772.html

JueCezhuli (2020). What Is "New Infrastructure" and Its Projects. http://www.jue-ce.com/gupiaozhishi/gupiaorumen/1040.html 
Liang, S. T. (2020). The "New Infrastructure", 22,000 Projects, Nearly 50 Trillion Yuan of Investment to Be Launched! https://www.sohu.com/a/380846820_237556

Long, X. L. (2020). After Printing \$2 Trillion, the FED Is Printing Money More Slowly. Is the Crisis Over? https://new.qq.com/omn/20200421/20200421A0JBMI00.html

Mofcom (2020). The Bank of Canada Made Another Emergency Cut: Its Benchmark Interest Rate Is Now $0.25 \%$.

http://www.mofcom.gov.cn/article/i/jyjl/1/202004/20200402958375.shtml

Sina (2020a). Financial News.

http://finance.sina.com.cn/stock/relnews/us/2020-03-04/doc-iimxyqvz7664918.shtml

Sina (2020b). How Should Countries Respond to the Economic Impact of the Epidemic. http://news.sina.com.cn/w/2020-03-17/doc-iimxxstf9812163.shtml

Sina (2020c). Online News. https://cj.sina.com.cn/articles/view/1664176597/633151d502000tra2?from=finance

Tian, J. T. (2020). How to Understand the Meaning of "New Infrastructure", Internet Frontiers, Tencent Research Institute. https://www.tisi.org/13371

Weilai (2020). How Can Countries Cope with the Epidemic. http://dy.163.com/v2/article/detail/F8H8JL340518DC16.html

Reference News (2020). Online News. https://baijiahao.baidu.com/s?id=1660377419485002322

Wuhu (2020). A Sudden! Central Bank Cuts Interest Rate Again and Cut Reserve Requirement Ratio! http://wuhu.house.163.com/20/0423/10/FAT0U35I03270NMR.html

Yang, P. P. (2020). National Policies and Lessons to Cope with the Economic Impact of the Epidemic.

http://www.iwep.org.cn/xscg/xscg_sp/202004/W020200406080948693893.pdf

Zhi, C. (2020). The Latest News of Cutting Rate and the Expectation in the Future. http://www.zhicheng.com/gncj/n/329340.html 